By MURRAY L. BOB

\title{
The Nature of Staff Reading
}

Mr. Bob is librarian, General Information Department, Free Library of Philadelphia.

$\mathrm{T}$ HE DISCUSSION of staff reading ${ }^{1}$ which has appeared thus far in the pages of COLLEGE AND RESEARCH LIBRARIES has been primarily pragmatic. Certainly both Drs. Muller and Burton are for the most part concerned with the formulation and implementing of practical schemes to increase staff reading. Mr. Yerke, on the other hand, deals to a larger extent with the premises and probable consequences of such programs. It is with the latter aspects of the problem that this paper too is concerned.

A number of fundamental although substantially unexamined assumptions recur throughout the discussion. In the order of their appearance in Dr. Muller's seminal essay, they are: (I) "Well-read librarians seem to be in danger of becoming extinct." (2) "This trend might be related to the widely accepted policy of not permitting any protracted library staff reading on paid library time. ..." Mr. Yerke derives the same tendency from different origins: "... much librarianship is changing to administrative and technical manipulation."

Though not perhaps neatly stated in so many words, the supposal that extensity of staff reading is a positive circumstance is implicit, if not central, to Dr. Muller's point of view.

1 Muller, Robert H., "A Program for Staff Reading." COLLEGE AND RESEARCH LIBRARIES, I4: 235-239, July, I953. Yerke, Theodore B., "When Is A Librarian WellI953. "Y erke, Thllege AND RESEARCH LIBRARIES, I5: 2 IO-2II, Read?" COLLEGE AND RESEARCH LIBRARIES, I5: 210-2I I,
April, I954. Burton, Howard A., "Maximum Benefits April, I954. Burton, Howard A., "Maximum Benefits
from a Program for Staff Reading." SEARCH LIBRARIES, I 5: 277-280, July, I 954.
The first and third points are almost in the nature of articles of faith for the librarian. Nonetheless, or perhaps just because of this, they require close inspection. The contention that pre-Dewey librarians were never truly well-read, in Dr. Muller's sense, may be advanced with some justice. For neither a wide reading background nor the urge to "keep up with the literature," both so typical of educated people, including librarians, in our own day, were generalized among the learned in former times. "Wellread" meant something quite different then, to wit, a thorough grounding in that common core of knowledge designated as the classics. The delightful Franklin, who as much as any may be said to have sired the American library, wrote: "Read much, but not many books." There is a large amount of literary evidence to suggest that this neoclassic attitude was the ordinary one among savants, persisting until relatively late in the I 9 th century, although tempered toward the last by that taste for the exotic which was a mark of the burgeoning romanticism.

The roots of the foregoing attitude were embedded in numerous classical dicta against attempting the unreasonable; and the frenzied effort to keep up with a snowballing literature would have been accounted irrational. To read or study ${ }^{2}$ only that which could be read or studied thoroughly was the sovereign intellectual receipt of the age. The consequence, insofar as Dr. Muller et al., are concerned, is that there never was perhaps such a creature as the "well-

\footnotetext{
2 The two concepts were more nearly interchangeable in a day when both pleasure and intellectual profit were expected from every good book. In our time, they tend to be dichotomized in separate literatures.
} 
read librarian," given the contemporary understanding of the concept "well-read."

Even without historical antecedence, however, the notion of the positive value of extensive reading is worth investigation. Dr. Burton, himself a proponent of this view, wrote: "It should be remembered that an understanding of ideas is the paramount purpose in reading..." Utilizing this criterion I would say that the minimum obligations of the librarian to culture are not defined by whether or not he has a broad knowledge of the outside or even the inside of books. Far more important is the existence of an operational acquaintance with the basic ideas of the humanities and sciences.

It is impossible for the non-specialist (and the librarian may usually be accounted such in all fields save librarianship) to be aware of each empiric increment made to theoretic fundamentals. Therefore, the librarian's general training ought to be identical with that of any educated non-expert. It should be sufficient to enable one to say that none of countless new data is in principle alien to him. He could become thoroughly familiar with the material were it necessary for him to do so, inasmuch as he would have a broad (not to be confused with superficial) understanding of the focal conceptions in all areas of learning. Such understanding would permit the professional to locate at least proximately in the spectrum of human knowledge recent findings of whatever nature. In a word, the gulf which separates many a librarian from personal cultivation as well as from the serious reading public is one of ideas.

The remaining assumptions requiring critical examination are those offered in explanation of the circumstance that the librarian is not well-read. Dr. Muller, as noted previously, relates this to the fact that libraries do not generally permit other than professional reading on paid time. In order to advance the discussion it is necessary to substitute the phrase "well-educated" for the one heretofore employed- "well-read"this, inasmuch as it is my contention that librarians never were well-that is widely - read. If the problem is indeed one of faulty education is it not more logical to place the blame for such a deficiency upon the more influential institutions of formal (the school) and informal (mass communication media) education than upon the library? This is not just another way to pass the proverbial buck. Recognition that the causes of unawareness lie deep is simply realism. While the library should do everything in its power to remedy staff inadequacies it cannot be held primarily responsible for them.

What exactly can libraries do to raise staff level? They can attempt to create a truly intellectual milieu at least within their own confines. If the professional's ordinary environment is to a certain extent hostile to culture all the more reason for his work environment to mother same. Such a milieu is produced by and compounded of many things which are interchangeably causes and effects of one another: a quality collection of books and serials; employment of a few librarians who are themselves scholars; service to scholarship; and-paid reading time. Be it noted that the last is only one of several (and not the most important) factors.

Mr. Yerke believes that cultural shortcomings in members of the profession are traceable to the increasingly administrative and technical character of librarianship. Yet, factually, less and less attention is being paid by the bulk of the profession to technical processes simply because the latter have improved to such an extent in the last few decades that they are now semiautomatic. Technical improvement, far 
from constituting an obstacle to the cultivation of librarians, for the first time makes such personal development truly practicable. That administration encroaches on the librarian's time cannot be denied. This is due to the increasing size of collections and of staffs necessary to service them. Technical innovation offers hope ${ }^{3}$ in this area, too, for it may soon render the more mechanical aspects of administration automatic. Nevertheless, irrespective of the most sanguine expectations, the problem of the interference of administrative duties with what are perhaps the more satisfying facets of librarianship still remains.

In addition to the three major premises explored in the above, there were two minor though related assumptions ventilated in the previous articles which bear attention. One was Dr. Burton's contention that rapid reading is good reading and slow reading the reverse. There is some validity to this principle, but it is hardly unexceptionable. While increased speed is undoubtedly of great value to the backward reader it does not necessarily have the same consequences for the good reader. Thus what would Dr. Burton do with the occasional book that requires many readings and/or note-taking along the way for its full value to be extracted? The rarity of such volumes is surely no index of their importance. Quite the contrary: these are the very books which shape our mind and thought. The deliberate reader who reads with pen in hand, jotting down reflections

3 In this connection it should be recalled that the large-scale application of technology to areas other than the industrial has only just begun. and conclusions as he proceeds, is really indulging in a creative act. Under such circumstances reading ceases to be merely a passive experience and becomes operational: ideas are fitted into frames of reference, and old frames of reference are bent to new concepts. This is the most fruitful way to read-and I fear that the rapid reading that Dr. Burton enjoins upon us would destroy both the taste and the possibility of developing the taste for such reading.

The "cult of coverage" attitude is also implicit in Dr. Muller's statement in connection with the possibilities for his proposed program of staff reading: ". . . all the most noteworthy new books could be read by even a relatively small staff provided that no two staff members would read the same book on library time." There is no better way to create a high-level universe of discourse between staff members than by shared intellectual experience. What better way to foster a milieu of intelligence than through mutual discussion, formal and informal, of important books and the ideas they contain?

In summation, though paid reading time is not in and of itself objectionable, the motives from which it appears to spring ("cult of coverage"), and the results expected from its promulgation alone (raising of the quality of library service) are subject to question. Paid reading time can contribute to elevating the level of the profession only if it is part of a larger program designed to generate and nourish an atmosphere of ideas in the library.

\section{Credit Due}

We apologize for the omission of the names of those who worked so hard to gather the "College and University Library Statistics, 1953-54." These were compiled by the following members of the ACRL Statistics Committee, chairmanned by Dale Bentz, State University of Iowa: Group I by Dale Bentz; Groups II and III by Dan Graves, Municipal University of Wichita; Teacher College Libraries by Wendell Smiley of East Carolina College, Greenville, N.C.-Editor's Note. 